\title{
DEVELOPMENT OF AN RFID SYSTEM FOR TRACKING CONSTRUCTION RESIDUAL SOIL IN TAIWAN
}

\author{
Rong-Yau Huang ${ }^{1}$ and $\underline{T s u n g-Y i ~ T s a i ~}^{2} *$ \\ ${ }^{1}$ Professor, Graduate Inst. of Constr. Eng. \& Mgmt, National Central University, Taoyuan, Taiwan \\ ${ }^{2} \mathrm{PhD}$ student, Graduate Inst. of Constr. Eng. \& Mgmt, National Central University, Taoyuan, Taiwan \\ * Corresponding author (9634050005@cc.ncu.edu.tw)
}

\begin{abstract}
A lot of construction residual soils are generated each year in major construction projects in Taiwan. Currently a Construction Residual Soil Report System (CRSRS) is implemented in Taiwan. It requires to report every month on the sources and destinations, as well as the amount of residual soils. The local government authorities will then audit those reports to check for any irregular movement and/or amount matching of residual soils. Not only the process is labor intensive, the reported data are prone for human errors purposely and unintentionally. Therefore, the effectiveness of the CRSTRS is often questioned. This research takes the advantages of the capabilities of RFID in identification and security, and the capabilities of on-line web system in real-time, and developed an integrated automatic system for tracking construction residual soils. The developed RFID system is validated through actual project testing. The initial results approve the effectiveness of the system. The system analysis, the framework as well as the various modules, the testing of the cases and the results are reported in this paper.
\end{abstract}

Keywords: RFID, Construction, Residual Soil, Automation

\section{INTRODUCTION}

More than 30 million cubic meters of construction residual soil is generated each year in major construction projects in Taiwan. These soils are usually transported from the jobsites to proper disposal sites for reuse, recycling or landfill. However, from time to time they are dumped illegally in the roadside, riverside or other remote areas for saving cost, which brings hazard to the public safety as well as the environmental soundness. Currently a Construction Residual Soil Report System (CRSRS) is implemented in Taiwan. In CRSRS, for tracking the transportation of construction residual soil and prevent illegal dumping relies on manual control sheets, which need to be signed by the project contractor, the carrier and the receiver. Besides, CRSRS also requires both the construction jobsites and the residual soil disposal sites to report every month on the sources and destinations, as well as the amount of residual soils. The local government authorities will then audit those reports to check for any irregular movement and/or amount matching of residual soils. Not only the process is labor intensive, the reported data are prone for human errors purposely and unintentionally. Therefore, the CRSRS is vulnerable to conspiracies among related parties, and its effectiveness is often questioned.

One way to improve the errors is to use a ubiquitous sensing and communications environment that can help record the time data when the truck arrive and leave. Radio Frequency Identification (RFID) has been broadly applied in object identification and tracking. This non-contact reading method which goes through the readers and tags can allow the user to obtain the basic information of objects. If RFID technology can be introduced to the construction residual soil tracking control to identify the related transport data, and apply real-time transmission and online comparison, it will assist in enhancing the current system in tracking the contraction residual soils. The tracking system can be automated and the labor requirements of the process can be reduced. In addition, the problems of conspiracies among related parties that 
frequently results in illegal dumping, can be alleviated to certain degree.

\section{OBJECTIVES}

The major objective of this research is to provide data communications to track the contraction residual soils using RFID technology. A prototype RFID construction residual soil tracking control system (RFID-CRSTCS) has been developed to test the feasibility in the real case.

The main procedures of the research are as following: (1) to plan a new control process; (2) to develop the prototype of RFID-CRSTCS, (3) to test the efficiency of the developed system at a job site and a disposal sites.

\section{THE RFID-CRSTCS MODEL DESIGN}

\subsection{THE EXPERT RECOMMENDATIONS}

Due to the CRSRS has to take manpower, that lead to human-errors and take more potential cost. The purpose of this research will develop an automatic and electronic system in the RFID environment. It will assist and improve the current management system and manual control sheets. In order to ensure that the new system processes and functions in accordance with actual demand, this research held expert meetings to clarify this system the difference with the actual needs and requirements.

Prospective candidates for the meetings include three general managers of disposal site, one architect, three engineering directors, one researcher of CRSRS, and one supervisor. Interviewees indicated a number of issues and concerns commonly expressed by transporting cost, management level, and carriers.

The expert recommendations are as following:

(1). To address the lack of instant records caused by the low traceability and opacity of the transporting data.

(2). To address the issue of storing and carrying information on manual control sheets.

(3). To consider the accuracy of RFID reading in terrible environment.

(4). To address the maintainability of the system caused by disconnected network or non-soil loading operation
(5). To consider the responsibilities of different stakeholders in jobsites or disposal sites.

(6). To consider the pricing and amount of transporting soils by combined RFID system with weighbridge.

\subsection{NEW MODEL CONCEPTS AND STEPS}

To check any irregular movement and/or amount matching of residual soils is a labor intensive process. Data acquisition and record involves the human-errors. Thus, instant and automatic data acquisition of management information from the utilization of an automatic information system could be a critical factor at the construction jobsites and the soil disposal sites.

According to the current management structure and expert recommendations, the major participants of new model are the local government authorities, soil disposal sites, carrier, and contractor, etc. The RFID-CRSTCS is designed to automatic upload, record and match information during the residual soils transporting operation using the RFID technology components, video camera and real-time web environment. The following are concepts and operating stages designed for the system upon the completion of visits, and the detailed schematic information flow model is illustrated in Fig. 1.

\section{Stage1 : Project applying}

At this stage, the project contractor will apply to county government for transporting construction residual soil by the transporting plan. Then, the contractor also adds a new project in RFID-CRSTCS, input the project basic information and select some cooperating contractors such as carrier, disposal sites, and competent authority.

The undertakers of local government will examine the transporting plan and get the authorized number form RFID-CRSTCS to print RFID tags. These tags with pre-set jobsite and residual soil disposal sites information will be attached to the windscreen of each truck in order to identify status and start transporting the soil. The tags' position is shown at Fig. 2.

\section{Stage2 : Residual soils transporting}

Before transporting, RFID equipment and the client side system shall be set up and installed at the jobsite and the residual soil disposal sites. When a truck enters and leaves the jobsite for loading the soil, the reader will read the tag 
and register the time through internet to the control server computer. At the same time, a camera will take photo of the truck when the tag is read. Later on when the truck arrives at the disposal sites, same procedure repeats and the time of arrival recorded in the server computer. The server computer can then match the record for completing a trip of a truck or detect any unusually truck travel. If the data is missing, it will be treated as the truck did not complete soil trip, and the system will automatically mark the state. On contrary, when the truck is confirmed to be normal, the control server computer will calculate and accumulate in real-time and then report the project residual soil transport amount to provide to related parties for online inquiry. The RFID based system is automatic and not prone to human error and manipulation. It, therefore, enhances the efficiency for tracking the construction residual soil.

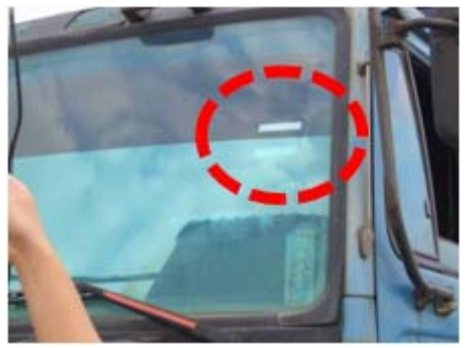

Fig. 2 RFID tag on the windscreen

\section{Stage3 : Data re-registration}

The primary link in this system is the Internet. Thus, when the contractor could not set up the hardware to link Internet access or the network has lower efficiency, the server computer maybe could not match the record for completing a trip of a truck. So, the data re-register stage will use the transporting information and photos from jobsites and disposal sites to redeem the lower efficiency of device or the error of internet

This stage can maintain the tag identification effect during system disconnection to avoid data losses and mistakes. The client system shall determine the connection status automatically. It will store the transporting data in the database at jobsites or disposal sites during disconnecting the Internet, and when the network is connected, batchupload the stored data. The data re-registration includes batch-uploading, manual- uploading and record amendment to ensure the accuracy and timeliness of transporting data. The contractor can apply for data reregistration to the competent authority according to the stored transporting records and photo. The competent authority will process related data re-registration according to the provided data to facilitate future statistical analysis.

\subsection{SYSTEM COMPONENTS}

RFID is a data acquisition method which is based on the detection of radio-frequency signals. An RFID-based system usually consists of various components such as tags, antennas, readers, and application system.

The RFID-CRSTCS is developed using Visual ASP. NET 2005 and Visual studio VB, and runs in Windows environment. The data storage is use SQL server 2005 Express. In addition, the RFID equipment and system related hardware is shown in Table 1.

Table 1 RFID-CRSTCS equipment and related hardware

\begin{tabular}{|c|c|c|}
\hline Item & Content & Note \\
\hline Frequency & UHF & Gen2 \\
\hline Tags & Sticker type, passive type & $\begin{array}{c}\text { AWID-MPR } \\
3014 \text { WF-OM }\end{array}$ \\
\hline Reader & Fixed & $\begin{array}{c}\text { AXIS 213 PTZ } \\
\text { Network Camera }\end{array}$ \\
\hline Camera & Webcam & customized \\
\hline $\begin{array}{c}\text { Warning } \\
\text { light }\end{array}$ & Three-colored warning light & \\
\hline
\end{tabular}

\section{RFID-CRSTCS FUNCTIONS INTRODUCTION}

The RFID-CRSTCS is established to achieve transporting process control, automatic information integration, and complete amount accumulate. This paper will probe into the procedure of systematic operation and the relation between users' demand and current regulations.

The system structure, shown in Fig. 3, has two sub-systems and six modules. The first sub-system, Project Registering sub-system, is web-based system that is the core of RFIDCRSTCS that provides registration for users and projects, and matches the transporting information from the jobsites and disposal sites. The other is Identifying sub-system that assists the site to identify the tag of each truck, and then upload the information to the Project Registering subsystem. 


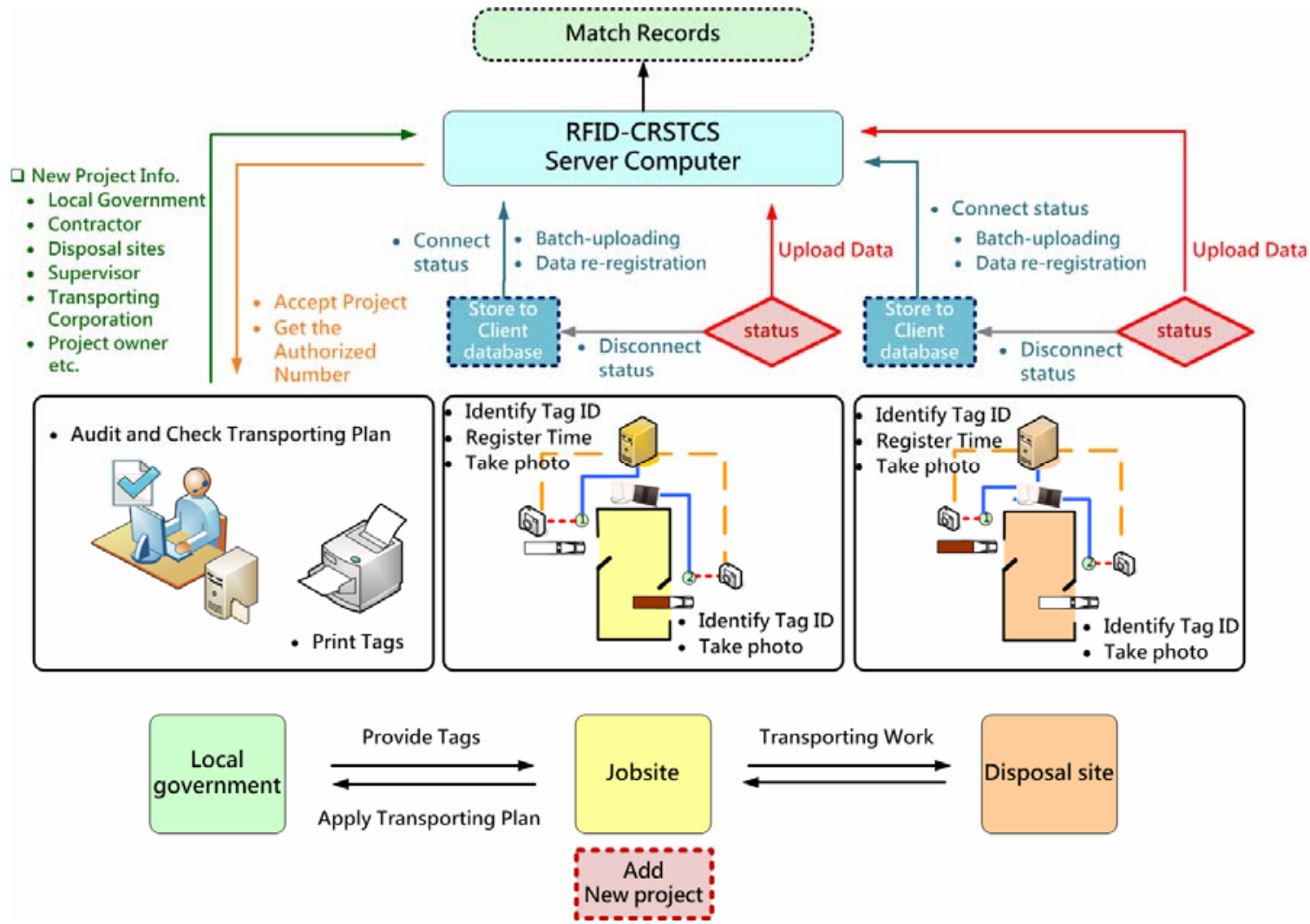

Fig. 1 Information flow model.

\subsection{Project registering sub-system}

Project registering sub-system is developed to provide users with some applications that allow registering the information of users, applying transporting project, reviewing progress, matching transporting information form jobsites and disposal sites. Modules and functions provided by this sub-system are discussed below:

\section{(1).User registration module}

User Registration is developed according to current manual control sheets. In this module, six type of authorization are provided that include local government, contractor, disposal sites, supervisor, transporting corporation and project owner. Due to types of users are different, this research designs some necessary columns such as username, password, address, telephone number, agency, E-mail address, fax number, etc. Besides the basic information necessity, the disposal sites must fill in the type and amount of construction residual soil. The example of user registration is shown in Fig. 3.

\section{(2).Project Registration module}

Project Registration provides contractor to register new transporting project, and then contractor must fill some basic information in include project name, jobsite address, type and quantity of soil, local government, disposal site, supervisor, transporting corporation and project owner.

\section{(3). Matching and Accumulating module}

Matching and Accumulating module can match the record from sites for completing a trip of a truck or detect any unusual truck travel, while will accumulate the transporting records of each project for the quantity of soil. The other function of this module provides local government and supervisor to review the progress and any unusual records.

\subsection{Identifying sub-system}

In this automatic control model, to match and accumulate the transporting information depends on Identifying subsystem. This sub-system is installed in jobsites and disposal sites, and its main functions provides users to print the authorized tags, read and check the number of tags, take a photo, record the arrival time and leaving time, upload data, etc. 


\section{(1).Equipment Installation module}

According to project registration, every project has only one project ID. This ID will cooperate with the license number of each truck to generate the authorized number that is coded for RFID tags. The agency of local government can use this module to print and code tags for identification. Besides, this system uses LAN to connect RFID reader, camera and warning light. Users must insert or edit the IP of these equipments to install and link.

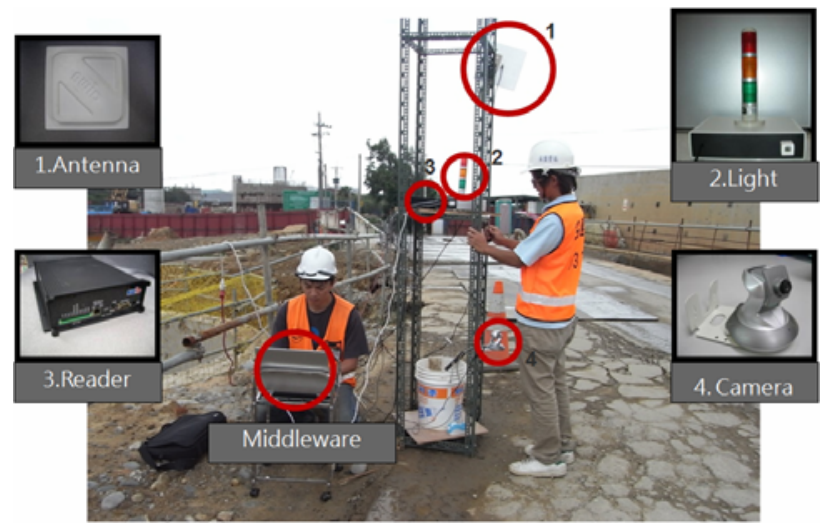

Fig. 4 Installation of RFID equipment

\section{(2).Tags Identification module}

This module will control the RFID reader to read and identify the authorized tags when trucks pass through the entrance of jobsites or disposal sites. At the same time, a camera will take a photo of each truck, and then upload data through internet to Project registering sub-system, waiting for matching.

\section{(3). Data Re-registration module}

When the system cannot identify or upload related data through the Internet to the Project Registering sub-system, it causes the operation performance to make mistakes. Therefore, this module stores the transporting data and photo into client database without the Internet, and provides two ways to re-uploading data like batchuploading, and manual-uploading.

\section{5 .EXPERIMENT RESULTS}

This research integrated the technique of RFID, video camera and the immediate uploading capability of Internet to develop RFID-CRSTCS for tracking the construction residual soil. This system should be tested on actual excavating jobsites to establish its effectiveness. The excavation project of the high speed rail station was selected as a case study to test the feasibility.

The experiment will be processed based on the current system. It will inspect the difference between the RFIDCRSTCS data and the sheet records to ensure the accuracy and stability. The arrival and leaving time are an index of the efficiency of the construction residual soils transporting. The main focus was therefore on the confirmation of realtime uploading data, while not interrupting transporting work.

It is found after summarizing the transporting record of the field-experiment, and analyzing the field problem and difference that the RFID-CRSTCS can completely record the time and photo of trucks with RFID tags. The data recorded in the system is shown in Table 2. It indicates that the system is accurate and stable (see column A, B, C and $\mathrm{D})$; therefore it shall meet the actual operation.

\section{CONCLUSIONS}

This research takes the advantages of the capabilities of the RFID and the real-time web system, and develops an integrated automatic system, RFID-CRSTCS, for tracking construction residual soils. It includes project application, field transport, and data re-registration stages. Through the actual field-testing, the system can stably and accurately records the tagged transport trucks, which demonstrates the system soundness. With the developed CRSTCM, the tracking process of existing system can be automated and the labor requirements can be reduced. In addition, the problems of conspiracies among related parties that frequently results in illegal dumping, can be alleviated to certain degree.

\section{REFERENCE}

[1].Sungwoo Moon, and Byongsoo Yang, "Effective Monitoring of the Concrete Pouring Operation in an RFIDBased Environment”, J. Comput. Civ. Eng. , Vol. 24(1), pp.109-116, 2010.

[2]. Ung-Kyun L., Joo-Heon K., Hunhee C., Kyung-In K., "Development of a mobile safety monitoring system for 
construction sites”, Automation in Construction, Vol.18(3), pp. 258-264, 2009.

[3].Chien-Ho K., "RFID-based building maintenance system”, Automation in Construction, Vol.18 (3), pp.275284, 2009.

[4].Samuel Y.L. Y., H. Ping T., J.C. W., S.C. T., "Developing a precast production management system using RFID technology”, Automation in Construction, Vol.18 (1), pp. 677 - 691, 2009.

[5].Chun-Ta T., Yi-chang C., Che-ming Chiang, Chi-ming L., “Combination of radio frequency identification (RFID) and field verification tests of interior decorating materials”, Automation in Construction, Vol.18(1), pp. 16-23, 2008.

[6].Sze-wing Leung, Stephen Mak, Bill L.P. Lee,” Using a real-time integrated communication system to monitor the progress and quality of construction works”, Automation in Construction, Vol.17(6), pp.749-75, 2008.

[7].Edward J. Jaselskis and Tarek El-Misalami, “Implementing Radio Frequency Identification in the Construction Process" , J. Constr. Engrg. and Mgmt., Vol129(6), pp. 680-688, 2003.

Table 2 Transporting data comparison list

\begin{tabular}{|c|c|c|c|c|c|c|c|c|c|}
\hline & & & & & & & & & Unit: minute \\
\hline $\begin{array}{c}\text { Transport } \\
\text { date }\end{array}$ & Plate No. & $\begin{array}{c}\text { Enter jobsite } \\
\text { (A) }\end{array}$ & $\begin{array}{c}\text { Exit jobsite } \\
\text { (B) }\end{array}$ & $\begin{array}{l}\text { Sheet } \\
\text { recorded } \\
\text { (C) }\end{array}$ & $\begin{array}{l}\text { (A) and (C) } \\
\text { difference }\end{array}$ & $\begin{array}{c}\text { Enter } \\
\text { disposal site } \\
\text { (D) }\end{array}$ & $\begin{array}{c}\text { Exit } \\
\text { disposal site (E) }\end{array}$ & $\begin{array}{c}\text { Sheet } \\
\text { collected } \\
\text { (F) }\end{array}$ & $\begin{array}{l}\text { (D) and (F) } \\
\text { difference }\end{array}$ \\
\hline $2010 / 03 / 26$ & NG397 & $11: 41$ & $11: 50$ & $11: 52$ & 2 & $12: 57$ & $13: 28$ & $13: 00$ & 3 \\
\hline $2010 / 03 / 26$ & 399AN & $13: 23$ & $13: 31$ & $13: 33$ & 2 & $14: 40$ & $14: 53$ & $14: 45$ & 5 \\
\hline $2010 / 03 / 26$ & 503GY & $13: 24$ & $13: 35$ & $13: 38$ & 3 & $14: 40$ & $14: 57$ & $14: 45$ & 5 \\
\hline $2010 / 03 / 26$ & $8 \mathrm{E} 555$ & $13: 25$ & $13: 37$ & $13: 41$ & 4 & $14: 50$ & $15: 03$ & $15: 00$ & 10 \\
\hline $2010 / 03 / 26$ & $277 \mathrm{GE}$ & $13: 50$ & 14:01 & $14: 00$ & 1 & $15: 11$ & $15: 30$ & $15: 15$ & 4 \\
\hline $2010 / 03 / 26$ & 396GV & $13: 54$ & $14: 04$ & $14: 05$ & 1 & $15: 11$ & $15: 25$ & $15: 15$ & 4 \\
\hline $2010 / 03 / 26$ & 817A1 & $13: 55$ & $14: 07$ & $14: 09$ & 2 & $15: 27$ & $15: 38$ & $15: 30$ & 3 \\
\hline $2010 / 03 / 26$ & 681A1 & $14: 27$ & $14: 39$ & $14: 40$ & 1 & $15: 39$ & $15: 53$ & $15: 43$ & 4 \\
\hline $2010 / 03 / 26$ & GXY50 & $15: 14$ & $15: 24$ & $15: 25$ & 1 & $16: 25$ & $16: 41$ & $16: 30$ & 5 \\
\hline $2010 / 03 / 26$ & NG397 & $15: 14$ & $15: 28$ & $15: 30$ & 2 & $16: 40$ & \multirow{3}{*}{$\begin{array}{c}\text { Disconnected } \\
\text { reader due to sun } \\
\text { overheating }\end{array}$} & $16: 45$ & 5 \\
\hline $2010 / 03 / 26$ & 471AN & $15: 34$ & $15: 44$ & $15: 45$ & 1 & $17: 01$ & & $17: 03$ & 2 \\
\hline $2010 / 03 / 26$ & 399AN & $15: 43$ & $15: 53$ & $15: 55$ & 2 & $16: 50$ & & $16: 55$ & 5 \\
\hline Note & $\begin{array}{l}\text { RFID } \\
\text { Manu }\end{array}$ & $\begin{array}{l}\text { STCS : (A), ( } \\
\text { ontrol sheet : }\end{array}$ & $\begin{array}{l}\text { (B), (D) and } \\
\text { (C) and (F) }\end{array}$ & & & & & & \\
\hline
\end{tabular}

(a)

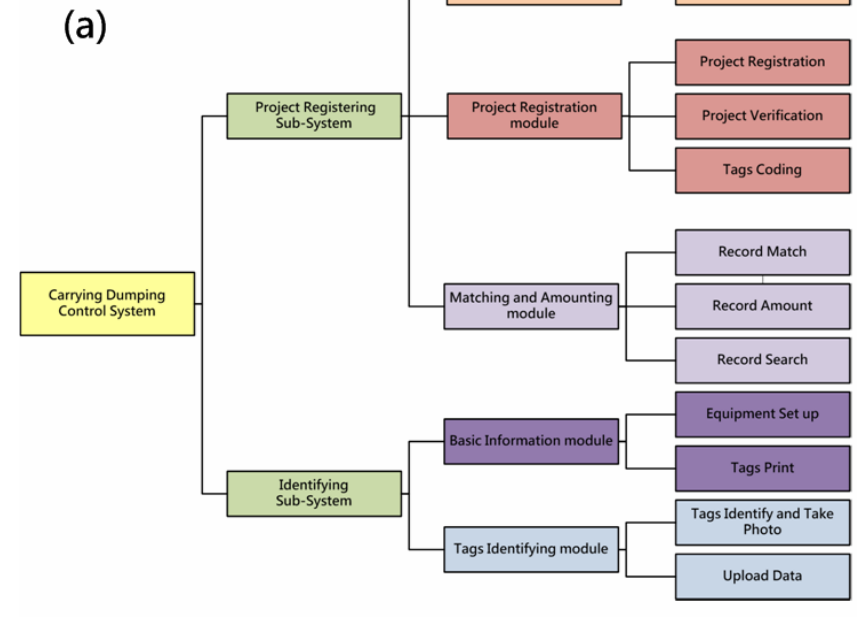

(b)

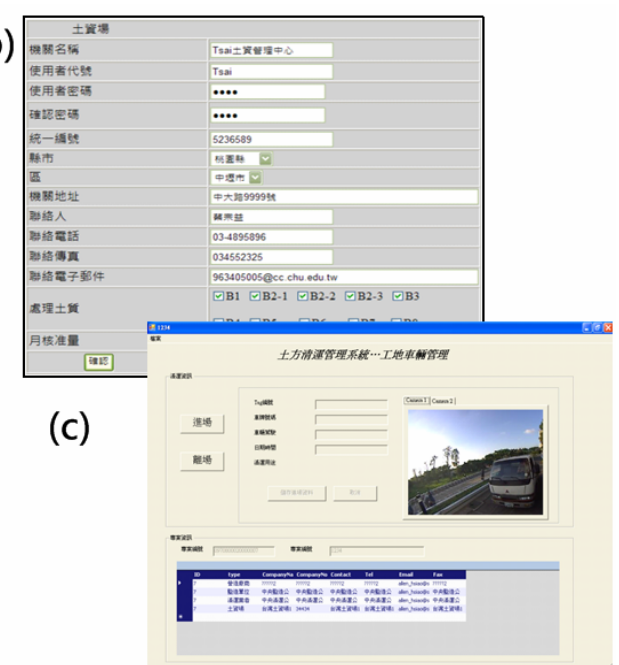

Fig. 3 (a) System structure; (b) An example of users’ registration; (c) An example of tags identifying 